\title{
Influence of graphic design of the text on reading quality of pupils with dyslexia
}

\author{
Pavel Zikl ${ }^{1 \mathrm{a}}$, Iva Košek Bartošová ${ }^{1}$, Kateřina Josefová Víšková ${ }^{1}$, Klára Havlíčková ${ }^{1}$, \\ Michaela Volfová ${ }^{1}$, and Barbora Zetková ${ }^{1}$ \\ ${ }^{1}$ Institute for Primary and Pre-Primary Education, Faculty of Education, University of Hradec \\ Králové, Rokitanskeho 62, Hradec Kralove, 500 03, Czech Republic
}

\begin{abstract}
The contribution contains research results focused on reading quality of pupils with dyslexia according to the graphic design of the text. Our aim was to prove if commonly recommended graphic text editing has a certain influence on reading speed and occurrence of mistakes of children with dyslexia. The research sample consisted of pupils with dyslexia and a control group then selected in pairs of intact pupils of 4th and 5th class of primary school (in total 150 pupils). For the purpose of data collection there had been a text used in an unfamiliar language (a nonsensical text, which corresponds to the Czech language in its structure; is a part of standardized reading test). There were four text versions prepared for the research which had been modified into frequently recommended modifications for dyslexics (increased font size, a use of bigger gaps between words and also rows, syllables highlight in words and a standard text corresponding to common reading-books). Conclusion depicts a presentation of impacts of individual texts modifications and also subjective opinions of pupils about these texts.
\end{abstract}

Keywords: specific learning disabilities; dyslexia; reading test; reeducation

\section{Introduction}

The main objective of the research was to compare the reading quality of pupils with dyslexia, namely speed and error rate in terms of both quality and quantity, in relation to the graphic design of the text. The choice of graphic modifications as a means of lowering the error rate and improving the reading speed of pupils with dyslexia is influenced by the fact that one of the biological causes of dyslexia is a dysfunction of the magnocellular system, which manifests itself by impaired visual perception $[5,6]$. A reader affected by the chaotic eye movements caused by the magnocellular system dysfunction has difficulties identifying for example letters in a word [8]. The research project The effect of print size on

\footnotetext{
${ }^{a}$ Corresponding author: pavel.zikl@uhk.cz
} 
reading speed in dyslexia [7], dealing with the influence of font size on reading speed in dyslectics, worked with the assumption that appropriate graphic modifications of the text may enable dyslectic pupils to reach the same curve of development as healthy individuals. The observations confirmed that reading under difficult visual conditions leads to a decreased reading performance of dyslectic individuals.

Motivation for the creation and realization of our research can be found in the fact that out of all specific learning difficulties, dyslexia is the one that influences the child's success at school the most, because it complicates all activities based on reading performance. The Orton Dyslexia Society defines dyslexia as "a specific speech disorder of constitutional origin characterized by problems with the decoding of individual words, usually reflecting an insufficient capacity for phonological processing" [8, p. 17]. Problems with the decoding of individual words often appear unexpectedly, with no relation to the child's age and his/her cognitive abilities, and they do not result from developmental disorders nor sensory damage [8]. The difficulty affects the basic variables of reading performance speed, correctness, reading technique and reading comprehension. Moreover, it causes difficulties with orientation in the text (repetition of the beginnings of words, skipping of lines etc.) and text reproduction. Incorrect reading or even mangling of words result in the so-called specific errors, which differ significantly in their occurrence and frequency in different languages. In Czech, they include static inversions (e.g. confusing letters of similar shapes such as b-d-p, a-o-e, m-n, l-k-h etc.), kinetic inversions (e.g. transposition of syllables), skipping or adding syllables, words or sentences, inappropriate use or omission of diacritics, or guessing of word endings.

\section{Research objectives and methods}

The aim of the research was to compare the reading quality of pupils with dyslexia in relation to the graphic design of the text. For the purposes of the research, the text modifications chosen were those recommended for dyslectic readers, i.e. highlighting of syllables, using larger font sizes and spaces between words and lines, in comparison with the font size and line spacing commonly used in reading-books for the analysed age group. The results of the reading tests using three graphically modified texts were then compared with the results obtained with the serif typeface Times New Roman of the standard size used in reading-books for the analysed age group in the Czech Republic. The research sample was composed of pupils with learning disabilities and the control group comprised pupils of the same age and school grade, but without SLD (creating pairs according to gender, age and school class). The test was administered in total to 150 pupils of the $4^{\text {th }}$ and $5^{\text {th }}$ grades of primary schools in cities and smaller municipalities.

We formulated the following hypotheses:

- H1: The graphically modified text will have a positive impact on the reading speed of dyslectic pupils in comparison with the regular text.

- H2: Graphic modifications of the text will lower the occurrence of errors in dyslectic pupils in comparison with regular text.

\subsection{Description of the research tool}

Since the data collection required repeated readings of the same text, we used a standardized text called "Latyš", which is written in an unfamiliar language. This text is a component of the standardized reading test used for the diagnosis of dyslexia. It is a nonsensical text, but its structure is nevertheless equivalent to Czech (the incidence of 
consonants/vowels, word length etc.) [4]. All the text tables in the different modifications were adapted to the standardized test - the same text, the same number of words per line, but different font size, line spacing etc. All the subtests used the serif typeface Times New Roman. Subtest 2 - text with a bigger font size - used a font size $0.5 \mathrm{~mm}$ larger (font size 3 $\mathrm{mm}$ ) than the standard text (font size $2.5 \mathrm{~mm}$ ). In subtest 3 - text with larger spaces between words and lines - the spaces between lines were $2.5 \mathrm{~mm}$ bigger than in the standard text, the spaces between words were $2 \mathrm{~mm}$ bigger. In subtest 4 - text with highlighted syllables - the font size and spacing corresponded to the standard text (MS Word 2010). The administration of the individual tests followed the standard procedures of the Reading Test (recording of mistakes, instructions etc.). Each pupil read the same text in all the four graphic modifications with 7 days between the readings. The interval was introduced in order to prevent children from remembering the text as well as from using their intelligence to compensate for their reading difficulties, which is the purpose of texts in an unknown language. In order to maximize objectivity, the pupils were divided into groups that read the texts in different orders. The administrators measured the reading speed of the children (number of words read during the first, second and third minute) and noted mistakes in a record sheet. After the end of the testing, the pupils were asked about their subjective opinion on how difficult they found the reading (they graded each text immediately after reading on the scale of 1 (best) to 5 (worst) like in school). At the very conclusion of the testing they were additionally asked to arrange the texts in the order in which they would be the easiest for them to read.

\subsection{Research sample}

The research sample comprised in total 150 pupils of the $4^{\text {th }}$ and $5^{\text {th }}$ grades of primary school with diagnosed dyslexia, the control group comprised intact pupils chosen in pairs with the dyslectic pupils (Table 1).

Table 1. Research sample.

\begin{tabular}{lccc}
\hline & number & age & $\begin{array}{c}\text { standard } \\
\text { deviation }\end{array}$ \\
\hline Intact pupils & $74-77$ & 10,28 & 0,81 \\
Pupils with dyslexia & $75-78$ & 10,36 & 0,83 \\
\hline
\end{tabular}

Note: The number of pupils differs slightly due to their absences at school (the administration of all subtests took six weeks for one pupil).

\section{Research results}

Table 2 presents the comparison of the number of correctly read words during the first minute. Naturally, a significant difference between the dyslectic pupils and the intact pupils is apparent, that was, however, not the main objective of the research. Pupils with dyslexia show a greater number of correctly read words with all three modified texts (S2, 23, S4) in comparison with the standard text (S1). When a bigger font was used (S2), the result was $9.7 \%$ better, and with the text where bold and normal print alternated to highlight syllables, the results were $11.5 \%$ better. These results were, however, not statistically significant. The only statistically significant difference was the improvement found with the text with larger spaces between lines and words. When this text was used, pupils with dyslexia read almost 6 words more, i.e. $23.1 \%$. We may therefore state that $\mathrm{H} 1$ was confirmed only for 
the S3 text (larger spaces between words and lines). A similar result was also found with the control group, i.e. the intact pupils.

Table 2. Number of correctly read words during the first minute.

\begin{tabular}{lcc}
\hline & $\begin{array}{c}\text { pupils with } \\
\text { dyslexia } \\
\text { number of words }\end{array}$ & $\begin{array}{c}\text { intact pupils } \\
\text { number of words }\end{array}$ \\
\hline S1 (regular text) & 25,12 & 45,53 \\
S2 (bigger font) & 27,55 & 49,55 \\
S3 (larger spaces between words and lines) & $\mathbf{3 0 , 9 2}$ & $\mathbf{5 2 , 7 9}$ \\
S4 (alternation of bold and normal print) & 28 & 50,35 \\
\hline
\end{tabular}

Note: The results in bold are statistically better in comparison with the regular font (S1).

Table 3 shows an overview of the number of mistakes made during the first minute of reading. When the modified texts were used the error rate decreased slightly, but the difference is not marked nor statistically significant. We may state that $\mathrm{H} 2$ was not confirmed for any of the kinds of graphic modification of the text.

Table 3. Number of mistakes made during the first minute.

\begin{tabular}{lcccc}
\hline & $\begin{array}{c}\text { pupils with } \\
\text { dyslexia } \\
\text { total number of } \\
\text { words read }\end{array}$ & $\begin{array}{c}\text { pupils with } \\
\text { dyslexia } \\
\text { number of } \\
\text { mistakes }\end{array}$ & $\begin{array}{c}\text { pupils with } \\
\text { dyslexia } \\
\text { percentage of } \\
\text { mistakes }\end{array}$ & $\begin{array}{c}\text { percentage of } \\
\text { mistakes made } \\
\text { by intact } \\
\text { pupils }\end{array}$ \\
\hline S1 (regular text) & 31,1 & 5,95 & $19,1 \%$ & $6,5 \%$ \\
S2 (bigger font) & 33,59 & 6,08 & $18,1 \%$ & $5,7 \%$ \\
$\begin{array}{l}\text { S3 (larger spaces between words } \\
\text { and lines) }\end{array}$ & 37,45 & 6,63 & $17,7 \%$ & $5,4 \%$ \\
$\begin{array}{l}\text { S4 (alternation of bold and normal } \\
\text { print) }\end{array}$ & 34,27 & 6,27 & $18,3 \%$ & $5,4 \%$ \\
\hline
\end{tabular}

The next part of the research focused on the subjective opinion of the pupils. Pupils with dyslexia usually fear reading, they are demotivated, and if they found one of the texts easier/more legible, it could be reflected in a more positive attitude towards reading and thus also in the results. While the modified text did get slightly better "marks" from the pupils (Table 4), the ratings were very individual and the pupils did not give preference to any one of the graphic modifications of the text.

Table 4. Subjective rating by the pupils.

\begin{tabular}{lcccccccc}
\hline & $\begin{array}{c}\text { How did you find the reading? } \\
\text { The pupils rated the text immediately } \\
\text { after reading (scale 1-5; 1 = best) }\end{array}$ & $\begin{array}{c}\text { Ordering of the subtests based on the } \\
\text { subjective opinion of the pupils (at } \\
\text { the end of the testing they ordered all } \\
\text { texts from best to worst: } 1-4)\end{array}$ \\
\hline pupils with dyslexia & $\mathrm{S} 1$ & $\mathrm{~S} 2$ & $\mathrm{~S} 3$ & $\mathrm{~S} 4$ & $\mathrm{~S} 1$ & $\mathrm{~S} 2$ & $\mathrm{~S} 3$ & $\mathrm{~S} 4$ \\
intact pupils & 2,69 & 2,53 & 2,40 & 2,56 & 2,72 & 2,22 & 2,53 & 2,54 \\
\hline
\end{tabular}




\section{Discussion}

The pupils with dyslexia reached the highest number of words read in one minute with the text with larger spaces between words and lines, which corresponds to the result of the research $[8,3]$ focused on the evaluation of the so-called persistence of visual stimuli - the image of a visual stimulus (letter, syllable) retained in our memory for processing for a longer time, when there is already a different stimulus in our field of vision. For this reason, an individual can consequently perceive letters, syllables and words that are close together as one chaotic image [2]. A similar view is held also by DeLamater [1], who mentions that larger spaces between neighbouring letters in a word reduces clustering and facilitates their identification, which should lead to a higher speed, but also to a lower error rate when reading.

The study called "The Effect of Font Size on Reading Comprehension on Second and Fifth Grade Children: Bigger Is Not Always Better" [7], dealing with the effect of font size on reading comprehension, found that for example font size, line length and line spacing have a greater influence on the reading performance of younger pupils, because readers' ability to decode progressively smaller text increases with age. We focused on the students of the fourth and fifth grades (i.e. older) and we did not observe a statistically significant improvement when the font size was modified either.

Pupils with dyslexia achieved better results, in terms of number of words read per time unit, with all the types of modification, and especially larger spaces between words and lines had a rather great impact. This leads to the assumption that their use for re-education or compensation of difficulties of individuals with SLD is not completely insignificant and it could be helpful to at least a certain group of pupils. On the other hand, a mechanical use of modified texts in reading-books (for example with the alternation of bold and normal print to mark syllables) or a simple enlargement of font size can have virtually no effect and it is not effective for re-education.

Individual differences between pupils can also be a relatively important factor, not only in terms of their subjective perception of the text (see Table 4), but also in terms of the use of the particular text modifications. For this reason, every re-education worker should test different modifications personally and be able to assess their impact on individual pupils, and should not use the same modifications for all.

Our previous research [9] focused on the impact of using a different typeface. We used a typeface created especially for dyslectics (OpenDyslexic) and the comparison showed that while this font did not increase reading speed, children found it subjectively easier to read. Its use reduced the incidence of mistakes in children with a severe form of dyslexia. This is meant to illustrate the fact that there is a high number of possible graphic modifications and they can be combined in various ways, which could increase their effect.

It would also be possible to discuss the question of whether even larger spaces between words and lines would lead to further improvement and where lies the limit where further enlargement starts being counterproductive. It is also possible that the results of bigger font size would be statistically significant if it was enlarged more than in our research. This could present a topic for further research.

\section{Conclusion}

Given the results of the research, the conclusion can be reached that while graphic modifications, as well as the use of a different typeface, are to a large extent an individual matter of every person with SLD, a certain positive impact on the improvement of reading 
quality of disabled individuals is nevertheless apparent. The most effective means for reeducation seems to be the enlargement of spaces between words and lines - increase in reading speed by $23 \%$. This opens the possibility to search for different ways of modifying texts that would lead to the optimization of reading conditions for individuals with SLD, for example combinations of various graphic modifications (a different typeface and bigger font size etc.). However, it is important not to forget the fact that the reading quality of pupils with dyslexia is affected by several factors, for example the pupil's motivation for and interest in reading, the choice of teaching method or sociocultural environment, not just the graphic design of the text. It is necessary to test different options, to keep pupils' individual preferences in mind, and not to rely on using one type of modification or a specific kind of workbook for all pupils. Nonetheless, the use of modifications of the graphic design of the text has its place in re-education, as its potential is quite significant due to minimal time and material requirements. A simple modification tested for a specific pupil can immediately increase reading speed or lower the incidence of errors by up to a quarter. A similar improvement in re-education is otherwise a matter of several months' work, and it would be a shame if the potential of graphic modifications went unused.

\section{References}

1. DeLamater, W. E., How Larger Font Size Impacts Reading and the Implications for Educational Use of Digital Text Readers. [online] [cit. 2015-01-27] available from: http://www.ereadia.com/research/How_Larger_Font_Size_Affects_Reading.pdf, (2010).

2. Felcmanová, L., Test zrakového vnímání (Testing visual perception). Praha: DYScentrum, ISBN 978-80-87581-02-5, (2013).

3. Jošt, J., Čtení a dyslexie (Reading and dyslexia). Praha: Grada, ISBN 978-802-4730301, (2011).

4. Matějček, Z. a kol., Zkouška čtení (Reading test). Bratislava: Psychodiagnostika, (1992).

5. Stein,J., Visual motion sensitivity and reading. [online] [cit. 2015-06-21] available from:http://www.google.cz/url?sa $=\mathrm{t} \& \mathrm{rct}=\mathrm{j} \& \mathrm{q}=\&$ esrc $=\mathrm{s} \&$ source $=$ web\&cd $=2 \& \mathrm{ved}=0 \mathrm{C}$

DkQFjAB\&url=http\%3A\%2F\%2Fwww.researchgate.net\%2Fpublication $\% 2 \mathrm{~F} 5588563$ Visual_motion_sensitivity_and_reading\%2Ffile $\% 2 \mathrm{~F} 79 \mathrm{e} 4150 \mathrm{f} 26 \mathrm{e} 7 \mathrm{~d} 03 \mathrm{dcd} . p d f \& e i=0 \mathrm{Z}$ kQU_6n-Mero7 $\overline{\mathrm{Ab}}$--

IGgDw\&usg=AFQjCNGtXX33vScM68mcM8YOhXBxpxRJAQ\&bvm=bv.61965928, d.ZGU, (2003).

6. Stein, J., Walsh, V., To see but not to read; the magnocellular theory of dyslexia. [online] [cit. 2015-06-21] available from: http://www.2020true.com/office/box_b/documents/A0002.pdf, (1997).

7. The Effect of Font Size on Reading Comprehension on Second and Fifth Grade Children: Bigger Is Not Always Better. [online] 2013 [cit. 2015-01-27] available from: http://www.plosone.org/article/info\%3Adoi\%2F10.1371\%2Fjournal.pone.0074061

8. Zelinková, O., Poruchy učení (Learning disabilities) Praha: Portál, ISBN 80-7178-8007, (2003).

9. Zikl, P., Košek Bartošová, I., Josefová Víšková, K., et al., The Possibilities Of ICT Use For Compensation Of Difficulties With Reading In Pupils With Dyslexia. In Procedia Social and Behavioral Sciences. [online] [cit. 2015-01-27] Volume 176, p. 915-922, available from: http://www.sciencedirect.com/science/journal/18770428/176, (2015). 